\title{
A novel preoperative plasma indicator to predict prognoses for patients with esophageal squamous cell carcinoma after radical esophagectomy: fibrinogen-to-lymphocyte ratio
}

This article was published in the following Dove Press journal:

Cancer Management and Research

\author{
Ningbo Fan (D) ${ }^{1, *}$ \\ Dongni Chen ${ }^{1} * *$ \\ Jiabo Zheng ${ }^{2}$ \\ Zhesheng Wen (1D) \\ Peng Lin' \\ 'Department of Thoracic Oncology, \\ State Key Laboratory of Oncology in \\ South China, Collaborative Innovation \\ Center for Cancer Medicine, Sun Yat-sen \\ University Cancer Center, Guangzhou \\ 510060, People's Republic of China; \\ ${ }^{2}$ Department of Gastrointestinal Surgery, \\ The First Affiliated Hospital, Sun Yat-Sen \\ University, Guangzhou 510080, People's \\ Republic of China
}

*These authors contributed equally to this work
Correspondence: Peng Lin

Department of Thoracic Oncology, State Key Laboratory of Oncology in South China, Collaborative Innovation Center for Cancer Medicine, Sun Yat-sen University Cancer Center, Guangzhou 510060 , People's Republic of China

Tel +8687343905

Fax +8687343905

Email dr_linpeng@163.com
Purpose: The inflammatory microenvironment and hemostatic system are involved in several stages of tumor progression. The aim of this study was to assess the prognostic effect of fibrinogen-to-lymphocyte ratio (FLR) in esophageal squamous cell carcinoma (ESCC) patients who underwent radical esophagectomy.

Patients and methods: We retrospectively reviewed 673 consecutive patients with ESCC who underwent radical esophagectomy from January 2009 to December 2012 at a major cancer hospital in Guangzhou, southern China. The cutoff points were defined by the X-tile software. The prognostic value of FLR for overall survival (OS), disease-free survival (DFS), and first-year mortality after surgery were analyzed using Cox proportional hazard regression model and logistic regression model. Survival was estimated by the Kaplan-Meier estimator and compared using the log-rank test.

Results: The optimal cutoff point of FLR was 3.03. Compared with the FLR-low $(\leq 3.03)$ group, the FLR-high $(>3.03)$ group included older patients $\left(\chi^{2}=7.267, P=0.007\right)$, showed higher postoperative overall morbidity $\left(24.7 \%\right.$ vs $\left.14.8 \%, \chi^{2}=5.414, P=0.020\right)$ and tended to die within one year $\left(23.5 \%\right.$ vs $\left.10.9 \%, \chi^{2}=10.871, P=0.001\right)$. The FLR-high group showed significant lower 5-year OS rates $(41.2 \%$ vs $53.7 \%$, log-rank=6.827, $P=0.009)$ and 5-year DFS rates $(35.3 \%$ vs $48.0 \%$, log-rank $=5.954, P=0.015)$ than the FLR-low group. Multivariate analyses suggested that high FLR was an independent negative predictor of OS (HR: 1.448, 95\%CI: 1.073-1.952, $P=0.015$ ), DFS (HR: 1.445, 95\%CI: 1.084-1.925, $P=0.012$ ) and first-year mortality (HR: 2.123 , 95\%CI: $1.157-3.898, P=0.015$ ).

Conclusion: The preoperative FLR level could be used as a simple, noninvasive, inexpensive, and potentially effective indicator to evaluate the prognosis of ESCC patients following radical esophagectomy.

Keywords: esophageal squamous cell carcinoma, prognostic indicator, fibrinogen, lymphocyte

\section{Introduction}

Esophageal cancer (EC) is one of the most common and fatal malignant tumors worldwide. ${ }^{1}$ In China, it is the third most prevalent and the fourth leading cause of cancerrelated death, of which the dominant histopathological type is esophageal squamous cell carcinoma (ESCC). ${ }^{2}$ Although radical esophagectomy is still the cornerstone for resectable tumors, recent evidence has indicated that neoadjuvant chemoradiotherapy followed 
by surgery is more appropriate for locally advanced ESCC. ${ }^{3,4}$ Therefore, evaluation of the risk for poor long-term outcomes during initial diagnosis is particularly important in devising a customized risk-adapted therapeutic strategy for individual patients with ESCC.

It is well established that tumor progression and prognosis are associated not only with the tumor's innate characteristics but also with the host's inflammatory microenvironment. ${ }^{5,6}$ Studies have also reported that several malignant tumors are associated with abnormalities of the hemostatic system. ${ }^{7,8}$ Several pretreatment indexes such as prognostic nutritional index (PNI), ${ }^{9}$ Glasgow Prognostic Score (GPS), ${ }^{10}$ platelet-tolymphocyte ratio (PLR), and neutrophil-to-lymphocyte ratio $(\mathrm{NLR})^{11}$ have been reported to be of prognostic value for overall survival (OS) in patients with ESCC. Considering that these indexes are based mostly on inflammatory condition, and seldom take coagulation state into consideration, it would be useful to identify a novel and convenient indicator regarding the prognosis for patients with ESCC linking inflammation and coagulation.

Fibrinogen, a protein synthesized by hepatocytes in the liver, circulates in the bloodstream andplays a vital role in blood clotting, fibrinolysis, and cellular and matrix interactions. ${ }^{12}$ Studies have indicated that plasma fibrinogen level correlates with tumor progression and tumor metastasis, with hyperfibrinogenemia independently predicting an unfavorable survival in solid tumors including EC. ${ }^{13,14}$ Lymphocyte is a routinely detected plasma indicator throughout the therapeutic process with regard to patients' immune status and was used in some prognostic indexes such as PNI, PLR, and NLR. It was reported that lymphopenia was associated with inferior survival outcome in several malignant tumors. ${ }^{15,16}$ Therefore, we hypothesized that the combination of fibrinogen and lymphocyte may provide a simple and objective prognostic index for ESCC patients.

In this study, we created a novel prognostic marker, fibrinogen-to-lymphocyte ratio (FLR), to evaluate its prognostic value in patients with ESCC who underwent radical esophagectomy. To the best of our knowledge, this is the first study to comprehensively assess the prognostic features of FLR in ESCC.

\section{Materials and methods}

\section{Patients}

A total of 824 consecutive patients with ESCC undergoing radical esophagectomy from January 2009 to December 2012 in Sun Yat-sen University Cancer Center, Guangzhou, China were retrospectively enrolled in this study. Eighty-one patients who underwent neoadjuvant therapy were excluded, as were 27 patients who did not achieve R0 resection, 16 patients who died within 3 months after surgery and 27 patients without the required clinical data. The final cohort included 673 patients. Patient characteristics, clinicopathological factors, surgical procedures, preoperative plasma fibrinogen levels, preoperative lymphocyte levels, and postoperative survival were recorded in each case. TNM classification was evaluated using the 8 th edition of AJCC cancer staging system. ${ }^{17}$ This retrospective study was approved by the Ethics Committee of Sun Yat-sen University Cancer Center.

\section{Fibrinogen and lymphocyte measurement}

The plasma fibrinogen and lymphocyte levels were routinely collected from blood samples at the first diagnosis within two weeks before surgery. Fibrinogen levels were measured using a latex-enhanced immunoturbidimetric assay and a Sysmex CA 7000 system (Sysmex Corporation ${ }^{\circledR}$, Kobe, Japan). Lymphocyte levels were analyzed using fluorescence flow cytometry through XN-9000 (Sysmex Corporation ${ }^{\circledR}$ ). The FLR was defined as the fibrinogen level $(\mathrm{g} / \mathrm{L})$ divided by lymphocyte level $\left(10^{9} / \mathrm{L}\right)$. The cutoff point of preoperative fibrinogen levels is $4.00 \mathrm{~g} / \mathrm{L}$, as recommended. The optimal cutoff points of preoperative lymphocyte levels and FLR were measured by the X-tile Software, ${ }^{18}$ with 1.40 for lymphocyte and 3.03 for FLR.

\section{Follow up}

All the patients were regularly followed up every 3 months during the first two years after surgery and then every 6 months after. The last follow-up date was November 2018 and 49 out of 673 patients $(7.3 \%)$ were lost to follow up. All the follow-up data were collected from Official Follow-up Department of our hospital. The primary endpoints are OS and disease-free survival (DFS), and the secondary endpoint is first-year mortality after surgery. This study was approved by the ethics committee of Sun Yat-sen University Cancer Center. Owing to the retrospective study design and analysis of clinical data, informed consent was formally waived by the Ethics Committee of Sun Yat-sen University Cancer Center. All research work in this study complied with the declaration of Helsinki.

\section{Statistical analysis}

Median and interquartile range (IQR) were used to describe non-normally distributed quantitative data. Chi-square $\left(\chi^{2}\right)$ test and Fisher's exact test were used for categorical variables, and 
the Mann-Whitney $U$-test was used for continuous variables. Survival was estimated by the Kaplan-Meier estimator and compared using the log-rank test. Univariate and multivariate Cox proportional hazard regression models were used to evaluate independent risk factors for OS and DFS by calculating the HR and 95\% CI. Univariate and multivariate logistic regression models were used to assess independent risks of first-year mortality. The start time was the day of operation while the end time was the day when endpoints occurred or the last follow-up day for censored data. Two-tailed $P$-value $<0.05$ corresponded to a statistically significant difference. All the data were analyzed using SPSS Statistics 24 (IBM Corporation, Armonk, NY, USA).

\section{Results}

\section{Patient characteristics}

The clinicopathological characteristics of 673 ESCC patients are shown in Table 1. The median age was 59 years (IQR: $54.0-65.5$ ), and $78.0 \%$ of the patients were males. Three hundred and eighty-four patients (57.1\%) underwent Sweet esophagectomy and 289 (42.9\%) patients went through surgery by either the McKeown or Ivor Lewis approach. We divided all the cases into two groups: the FLR-low $(\leq 3.03)$ group $(n=588)$ and the FLRhigh $(>3.03)$ group $(n=85)$. The FLR-high group included older patients $\left(\chi^{2}=7.267, P=0.007\right)$, showed higher postoperative overall morbidity $\left(24.7 \%\right.$ vs $14.8 \%, \chi^{2}=5.414$, $P=0.020)$ and tended to die within one year $(23.5 \%$ vs $\left.10.9 \%, \chi^{2}=10.871, P=0.001\right)$ when compared with the FLR-low group. There were no significant differences in gender, surgical approach, tumor location, tumor length, tumor differentiation, TNM stage and adjuvant therapy between FLR-high and FLR-low groups.

\section{FLR and survival}

The median follow-up time was 95.3 months (IQR: 82.7-102.2 months). The FLR-high group showed significant lower 5-year OS rates $(41.2 \%$ vs $53.7 \%$, log-rank $=6.827, P=0.009)$ and lower 5-year DFS rates $(35.3 \%$ vs $48.0 \%, \log$-rank=5.954, $P=0.015$ ) than the FLR-low group (Figure 1). Univariate Cox regression analysis (Table 2) indicated that gender, age, tumor length, pT status, $\mathrm{pN}$ status, adjuvant therapy, fibrinogen level, lymphocyte level, and FLR level were prognostic factors for OS; gender, surgical approach, tumor length, pT status, $\mathrm{pN}$ status, adjuvant therapy, fibrinogen level, and FLR level were prognostic factors for DFS. Multivariate Cox regression analysis
(Table 3) indicated that older age, deeper tumor invasion, more lymph node metastasis, and higher FLR level were significantly associated with poor $\operatorname{OS}(P=0.003, P=0.001, P$ $<0.001$ and $P=0.015$, respectively). Similarly, singleincision surgical approach, deeper tumor invasion, more lymph node metastasis, and higher FLR level were significantly associated with poor DFS $(P=0.001, P=0.012, P<$ 0.001 and $P=0.012$, respectively). Notably, compared with the FLR-low group, the FLR-high group independently predicted a worse OS (HR: 1.448, 95\%CI: 1.073-1.952, $P=0.015$ ) and a worse DFS (HR: 1.445, 95\%CI: 1.084-1.925, $P=0.012$ ) in patients with ESCC.

\section{FLR and first-year mortality}

Eighty-four out of 673 patients (12.5\%) died within one year after surgery. Univariate and multivariate logistic regression analyses of risk factors for first-year mortality are shown in Table 4. Univariate analysis revealed that tumor length, pT status, pN status, overall morbidity, fibrinogen level, lymphocyte level, and FLR level were associated with first-year mortality. In multivariate analysis, FLR level along with tumor length, pN status and overall morbidity presented as independent predictive factors for first-year mortality $(P=0.015, P=0.023, P<0.001$ and $P=0.009$, respectively). Compared with the FLR-low group, the FLR-high group was independently associated with a higher risk of first-year mortality after surgery (HR: 2.123, 95\%CI: $1.157-3.898, P=0.015)$.

\section{Discussion}

Esophageal cancer is a highly aggressive disease with poor prognosis. ${ }^{2}$ Treatment options range from surgery, neoadjuvant/adjuvant therapy and radical chemoradiotherapy to various forms of supportive care in patients with ESCC. Decision-making among treatment options is usually determined by patients' tumor stage as well as general health condition. It is now generally accepted that an inflammatory microenvironment is an essential component of tumorigenesis, ${ }^{6}$ where increasing evidence has suggested that markers of systemic inflammation can effectively reflect tumor progression. $^{9-11}$ In this study, we proposed a novel inflammatory prognostic marker, fibrinogen-to-lymphocyte ratio (FLR), to evaluate its prognostic effect in ESCC patients who underwent radical esophagectomy.

Tumor cells activate the coagulation cascade by expressing procoagulant proteins such as tissue factor, heparinase, cancer procoagulant, and microparticles. ${ }^{7}$ Although the complete mechanisms of the relationship 
Table I Comparison of patients' characteristics between FLR-low and FLR-high groups

\begin{tabular}{|c|c|c|c|c|}
\hline Variables & $\begin{array}{l}\text { All patients } \\
(n=673)\end{array}$ & $\begin{array}{l}F L R \leq 3.03 \\
(n=588)\end{array}$ & $\begin{array}{l}\text { FLR }>3.03 \\
(n=85)\end{array}$ & $P$ \\
\hline $\begin{array}{l}\text { Gender } \\
\text { Male } \\
\text { Female }\end{array}$ & $\begin{array}{l}525(78.0 \%) \\
148(22.0 \%)\end{array}$ & $\begin{array}{l}452(76.9 \%) \\
136(23.1 \%)\end{array}$ & $\begin{array}{l}73(85.9 \%) \\
12(14.1 \%)\end{array}$ & 0.061 \\
\hline $\begin{array}{l}\text { Age } \\
\qquad 660 \\
>60\end{array}$ & $\begin{array}{l}384(57.1 \%) \\
289(42.9 \%)\end{array}$ & $\begin{array}{l}347(59.0 \%) \\
24 I(41.0 \%)\end{array}$ & $\begin{array}{l}37(43.5 \%) \\
48(56.5 \%)\end{array}$ & 0.007 \\
\hline $\begin{array}{l}\text { Surgical approach } \\
\text { Sweet } \\
\text { Ivor Lewis/McKeown }\end{array}$ & $\begin{array}{l}384(57.1 \%) \\
289(42.9 \%)\end{array}$ & $\begin{array}{l}334(56.8 \%) \\
254(43.2 \%)\end{array}$ & $\begin{array}{l}50(58.8 \%) \\
35(41.2 \%)\end{array}$ & 0.725 \\
\hline $\begin{array}{c}\text { Location } \\
\text { Upper } \\
\text { Middle } \\
\text { Lower }\end{array}$ & $\begin{array}{l}70(10.4 \%) \\
280(41.6 \%) \\
323(48.0 \%)\end{array}$ & $\begin{array}{l}59(10.0 \%) \\
248(42.2 \%) \\
28 I(47.8 \%)\end{array}$ & $\begin{array}{l}\text { II (I2.9\%) } \\
32(37.6 \%) \\
42(49.4 \%)\end{array}$ & 0.530 \\
\hline $\begin{array}{l}\text { Tumor length } \\
\begin{array}{l}\leq 4 \mathrm{~cm} \\
>4 \mathrm{~cm}\end{array}\end{array}$ & $\begin{array}{l}472(70.7 \%) \\
196(29.3 \%)\end{array}$ & $\begin{array}{l}420(71.9 \%) \\
164(28.1 \%)\end{array}$ & $\begin{array}{l}52(61.9 \%) \\
32(38.1 \%)\end{array}$ & 0.059 \\
\hline $\begin{array}{l}\text { Differentiation } \\
\text { GI } \\
\text { G2 } \\
\text { G3 }\end{array}$ & $\begin{array}{l}125(18.6 \%) \\
344(51.1 \%) \\
204(30.3 \%)\end{array}$ & $\begin{array}{l}97(\mid 8.0 \%) \\
28 \mid(52.1 \%) \\
16 \mid(29.9 \%)\end{array}$ & $\begin{array}{l}28(20.9 \%) \\
63(47.0 \%) \\
43(32.1 \%)\end{array}$ & 0.603 \\
\hline $\begin{array}{l}\text { pT category } \\
\text { T1 } \\
\text { T2 } \\
\text { T3 }\end{array}$ & $\begin{array}{l}81(12.0 \%) \\
138(20.5 \%) \\
454(67.5 \%)\end{array}$ & $\begin{array}{l}76(12.9 \%) \\
119(20.2 \%) \\
393(66.8 \%)\end{array}$ & $\begin{array}{l}5(5.9 \%) \\
19(22.4 \%) \\
61(71.8 \%)\end{array}$ & 0.175 \\
\hline $\begin{array}{l}\text { pN category } \\
\text { N0 } \\
\text { NI } \\
\text { N2 } \\
\text { N3 }\end{array}$ & $\begin{array}{l}358(53.2 \%) \\
182(27.0 \%) \\
100(14.9 \%) \\
33(4.9 \%)\end{array}$ & $\begin{array}{l}319(54.3 \%) \\
151(25.7 \%) \\
90(15.3 \%) \\
28(4.8 \%)\end{array}$ & $\begin{array}{l}39(45.9 \%) \\
31(36.5 \%) \\
10(11.8 \%) \\
5(5.9 \%)\end{array}$ & 0.172 \\
\hline $\begin{array}{l}\text { TNM stage } \\
\text { I } \\
\text { II } \\
\text { III } \\
\text { IV }\end{array}$ & $\begin{array}{l}19(2.8 \%) \\
220(32.7 \%) \\
401(59.6 \%) \\
33(4.9 \%)\end{array}$ & $\begin{array}{l}18(3.1 \%) \\
187(31.8 \%) \\
355(60.4 \%) \\
28(4.8 \%)\end{array}$ & $\begin{array}{l}\text { I (I.2\%) } \\
33(38.8 \%) \\
46(54.1 \%) \\
5(5.9 \%)\end{array}$ & 0.435 \\
\hline Adjuvant therapy & $169(25.1 \%)$ & $152(25.9 \%)$ & $17(20.0 \%)$ & 0.245 \\
\hline Overall morbidity & $108(16.0 \%)$ & 87 (I4.8\%) & 21 (24.7\%) & 0.020 \\
\hline First-year mortality & $84(12.5 \%)$ & $64(10.9 \%)$ & $20(23.5 \%)$ & 0.001 \\
\hline Follow-up time (Median, IQR) & $95.3(19.5)$ & $95.8(19.7)$ & $92.3(21.3)$ & 0.502 \\
\hline
\end{tabular}

Note: Data in bold indicate significant differences.

Abbreviation: FLR, fibrinogen-to-lymphocyte ratio.

between fibrinogen and tumor progression have not been entirely elucidated, several underlying mechanisms may explain the prognostic value of fibrinogen in cancer. It was reported that fibrinogen binds to several growth factors such as platelet-derived growth factor (PDGF), fibroblast growth factor (FGF), TGF- $\beta$ and neurotrophin 

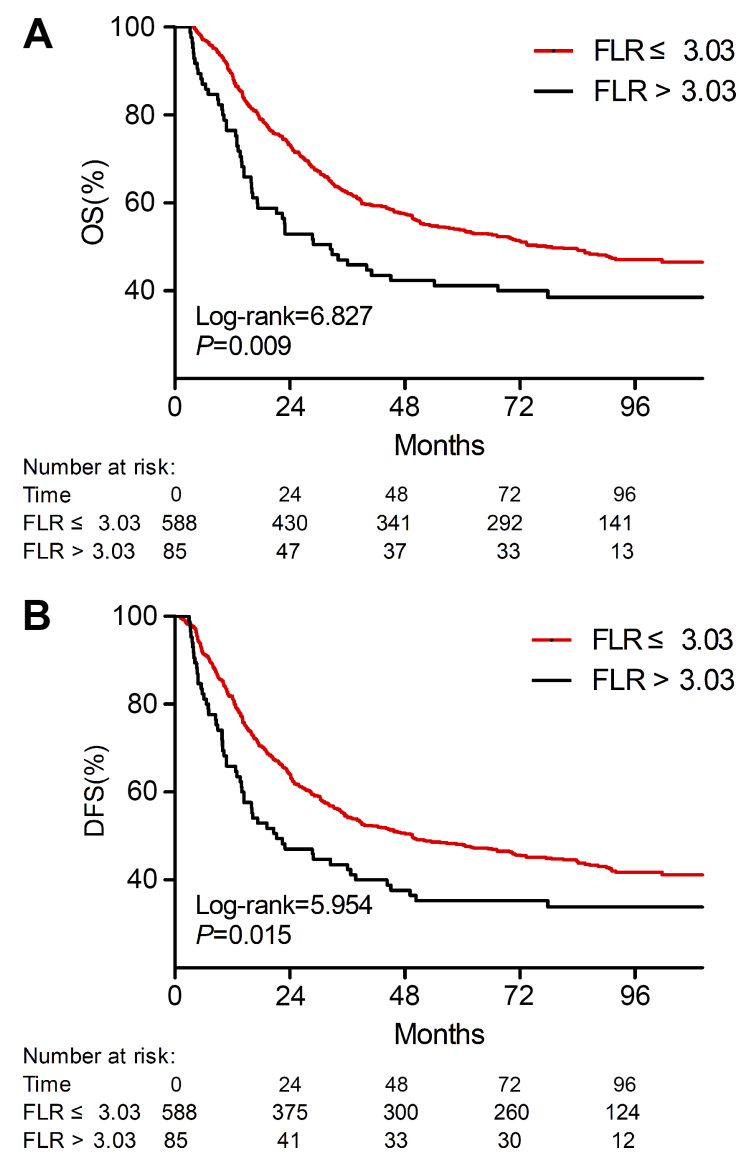

Figure I Kaplan-Meier curves for (A) overall survival and (B) disease-free survival in the FLR-high group and FLR-low group.

Abbreviations: OS, overall survival; FLR, fibrinogen-to-lymphocyte ratio; DFS, disease-free survival.

families. ${ }^{19}$ Those growth factors have been implicated in cancer progression by enhancing tumor cell proliferation and invasion as well as inhibiting apoptosis. ${ }^{20}$ Likewise, $^{2}$ fibrinogen stimulates tumor angiogenesis by motivating migration of endothelial cells through both chemotactic and chemokinetic activity and by enhancing the proangiogenic effects of vascular endothelial growth factor (VEGF) and FGF. ${ }^{21}$ In addition, fibrinogen was also recognized as a modulator of inflammatory processes that played a prominent role in regulating inflammatory response. $^{22}$ Jennewein et al in their review concluded that fibrinogen altered inflammation by not only inducing leukocyte migration but also modulating leukocytes and endothelial cells via an increased cytokine/chemokine response. $^{23}$ Steinbrecher et al in their animal experiment revealed that $\alpha \mathrm{M} \beta 2$-mediated engagement of fibrinogen was mechanistically coupled to local inflammatory processes and epithelial alterations that contributed to adenoma formation, which showed a unique link between fibrinogen and the development of inflammation-driven malignancy. ${ }^{24}$ Furthermore, studies have firmly suggested that fibrinogen plays a critical role in cancer metastasis in part by limiting natural killer cell (NK cell) function to protect tumor cells from NK cell-mediated lysis, which provided a clue linking fibrinogen to the immune system. $^{25,26}$ It is generally accepted that immune cells affect malignant cells with both tumor-suppressive and tumor-promoting effects. ${ }^{6}$ Lymphocytes are commonly used in monitoring indexes to assess the state of patients' immune systems. A low lymphocyte count may be associated with an immunosuppressed condition, which can predispose to tumor development. ${ }^{27}$ Several studies have suggested that pretherapeutic lymphopenia independently correlates with inferior OS in some cancers. ${ }^{15,16}$ Therefore, based on the well-accepted theory that crosstalk exists among coagulation, inflammation, immune response, and cancer development, the fibrinogen-tolymphocyte ratio may combine the predictive effects of both fibrinogen and lymphocyte and present a mixed prognostic value.

Our study demonstrated that preoperative FLR level could act as an independent prognostic marker for ESCC patients, where higher FLR was significantly associated with poor OS, poor DFS and higher incidence of first-year mortality after surgery. Multivariate analysis suggested that FLR was independent of fibrinogen, lymphocyte, and pathological $\mathrm{T} / \mathrm{N}$ status. Meanwhile, there were no significant differences between the FLR-high group and the FLR-low group with regard to pathological $\mathrm{T} / \mathrm{N}$ status and TNM stage, unlike previously described indexes such as PNI, NLR, PLR, GPS and fibrinogen alone. ${ }^{9,10,13} \mathrm{We}$ hypothesize that this may be because the FLR level reflects more about the host's systemic status than tumor burden. Further investigations are required to provide relevant evidence to strengthen this argument.

In addition to OS and DFS, we observed another endpoint, first-year mortality after surgery, which was seldom reported by former studies. Pines et al reported that first-year mortality after subtotal esophagectomy was correlated with positive lymph nodes, which was consistent with our finding that a higher $\mathrm{pN}$ status was independently associated with a higher risk of death within one year (Table 4). ${ }^{28}$ Nassri et al reported that a lower level of albumin was found to be an independent predictor of death within 6 months, and a lower plasma albumin level usually indicated that the body was in a nutritional deficit. ${ }^{29}$ Thus, we assume that early mortality after surgery may be related to both advanced tumor stage as 
Table 2 Univariate Cox regression analysis for overall survival and disease-free survival

\begin{tabular}{|c|c|c|c|c|}
\hline \multirow[t]{2}{*}{ Variables } & \multicolumn{2}{|l|}{ Overall survival } & \multicolumn{2}{|c|}{ Disease-free survival } \\
\hline & HR (95\%Cl) & $P$ & HR (95\%Cl) & $P$ \\
\hline \multicolumn{5}{|l|}{ Gender } \\
\hline Female* vs male & I.4II (I.077-I.849) & 0.013 & $1.315(1.021-1.693)$ & 0.034 \\
\hline \multicolumn{5}{|l|}{ Age } \\
\hline$\leq 60 *$ vs $>60$ & $1.280(1.040-1.576)$ & 0.020 & $1.136(0.93 \mathrm{I}-1.386)$ & 0.209 \\
\hline \multicolumn{5}{|l|}{ Surgical approach } \\
\hline Sweet & I (reference) & & I (reference) & \\
\hline Ivor Lewis/McKeown & $0.831(0.673-1.027)$ & 0.087 & $0.784(0.640-0.961)$ & 0.019 \\
\hline Location & & 0.160 & & 0.166 \\
\hline Upper & I (reference) & & I (reference) & \\
\hline Middle & $0.867(0.618-1.216)$ & 0.408 & $0.949(0.68 \mathrm{I}-1.322)$ & 0.755 \\
\hline Lower & $0.745(0.532-1.042)$ & 0.086 & $0.793(0.57 I-1.103)$ & 0.169 \\
\hline \multicolumn{5}{|l|}{ Tumor length } \\
\hline$\leq 4 \mathrm{~cm}^{*}$ vs $>4 \mathrm{~cm}$ & 1.335 (1.070-1.666) & 0.010 & $1.260(1.017-1.560)$ & 0.035 \\
\hline Differentiation & & 0.160 & & 0.153 \\
\hline GI & I (reference) & & I (reference) & \\
\hline G2 & 1.299 (0.966-1.748) & 0.084 & $1.24 \mid(0.936-1.643)$ & 0.133 \\
\hline G3 & $1.342(0.976-1.845)$ & 0.070 & $1.344(0.995-1.816)$ & 0.054 \\
\hline PT category & & $<0.001$ & & $<0.001$ \\
\hline TI & I (reference) & & I (reference) & \\
\hline $\mathrm{T} 2$ & $1.792(1.131-2.840)$ & 0.013 & $1.711(1.120-2.613)$ & 0.013 \\
\hline T3 & 2.527 (1.677-3.809) & $<0.001$ & $2.257(1.549-3.288)$ & $<0.001$ \\
\hline pN category & & $<0.001$ & & $<0.001$ \\
\hline No & I (reference) & & I (reference) & \\
\hline NI & $2.235(1.738-2.873)$ & $<0.001$ & $2.155(1.700-2.732)$ & $<0.001$ \\
\hline N2 & $3.521(2.666-4.649)$ & $<0.001$ & $3.478(2.663-4.542)$ & $<0.001$ \\
\hline N3 & $4.680(3.14 I-6.973)$ & $<0.001$ & $4.184(2.82 I-6.205)$ & $<0.001$ \\
\hline \multicolumn{5}{|l|}{ Overall morbidity } \\
\hline No* vs Yes & $1.089(0.824-1.440)$ & 0.548 & $0.937(0.7 \mid 2-1.234)$ & 0.644 \\
\hline Adjuvant therapy & $1.530(1.221-1.916)$ & $<0.001$ & $1.700(1.37 \mathrm{I}-2.107)$ & $<0.001$ \\
\hline \multicolumn{5}{|l|}{ Fibrinogen (g/L) } \\
\hline$\leq 4.0 *$ vs $>4.0$ & $1.382(1.106-1.726)$ & 0.004 & $1.333(1.078-1.650)$ & 0.008 \\
\hline \multicolumn{5}{|l|}{ Lymphocyte $\left(10^{9} / \mathrm{L}\right)$} \\
\hline$\leq 1.40 *$ vs $>1.40$ & $0.729(0.566-0.939)$ & 0.014 & $0.794(0.62 \mid-1.014)$ & 0.065 \\
\hline \multicolumn{5}{|l|}{ FLR } \\
\hline$\leq 3.03 *$ vs $>3.03$ & $1.476(1.100-1.981)$ & 0.009 & $1.420(1.070-1.884)$ & 0.015 \\
\hline
\end{tabular}

Notes: *Refer to reference category. Data in bold indicate significant differences.

Abbreviation: FLR, fibrinogen-to-lymphocyte ratio.

well as patients' poor health condition, which may be both reflected by higher FLR level. FLR may be the first inflammatory preoperative index linking OS, DFS, and first-year mortality after surgery in ESCC patients undergoing radical esophagectomy. Given the importance of patient risk stratification in deciding the most beneficial treatment, we propose that FLR could help identify those patients with a higher risk of poor outcome, for whom multidisciplinary therapy, intensive perioperative care, and close follow-up would then be highly recommended. Therefore, as an easily acquired, lowcost and repeatable index, FLR may serve as a promising indicator supplementing TNM staging system to improve 
Table 3 Multivariate Cox regression analysis for overall survival and disease-free survival

\begin{tabular}{|c|c|c|c|c|}
\hline \multirow[t]{2}{*}{ Variables } & \multicolumn{2}{|l|}{ Overall Survival } & \multicolumn{2}{|c|}{ Disease-free Survival } \\
\hline & HR (95\%Cl) & $P$ & HR (95\%Cl) & $P$ \\
\hline $\begin{array}{l}\text { Gender } \\
\text { Female vs male }\end{array}$ & & 0.243 & & 0.464 \\
\hline $\begin{array}{l}\text { Age } \\
\qquad \leq 60 * \text { vs }>60\end{array}$ & 1.375 (1.113-1.698) & 0.003 & & \\
\hline $\begin{array}{l}\text { Surgical approach } \\
\text { Sweet } \\
\text { Ivor Lewis/McKeown }\end{array}$ & & & $\begin{array}{l}\text { I (reference) } \\
0.711(0.579-0.874)\end{array}$ & 0.001 \\
\hline $\begin{array}{l}\text { Tumor length } \\
\leq 4 \mathrm{~cm} \text { vs }>4 \mathrm{~cm}\end{array}$ & & 0.552 & & 0.679 \\
\hline $\begin{array}{l}\text { pT category } \\
\text { T1 } \\
\text { T2 } \\
\text { T3 }\end{array}$ & $\begin{array}{l}\text { I (reference) } \\
\text { I.575 (0.99I-2.502) } \\
2.088(1.382-3.157)\end{array}$ & $\begin{array}{l}\mathbf{0 . 0 0 1} \\
0.055 \\
<\mathbf{0 . 0 0 1}\end{array}$ & $\begin{array}{l}\text { I (reference) } \\
\text { I.585 (I.036-2.425) } \\
\text { I.733 (1.210-2.596) }\end{array}$ & $\begin{array}{l}0.012 \\
0.034 \\
0.003\end{array}$ \\
\hline $\begin{array}{l}\text { pN category } \\
\text { N0 } \\
\text { NI } \\
\text { N2 } \\
\text { N3 }\end{array}$ & $\begin{array}{l}\text { I (reference) } \\
2.140(1.663-2.754) \\
3.532(2.667-4.677) \\
4.833(3.225-7.24 I)\end{array}$ & $\begin{array}{l}<0.001 \\
<0.001 \\
<0.001 \\
<0.001\end{array}$ & $\begin{array}{l}\text { I (reference) } \\
2.205(1.734-2.803) \\
3.616(2.75 I-4.752) \\
4.089(2.749-6.083)\end{array}$ & $\begin{array}{l}<0.001 \\
<0.001 \\
<0.001 \\
<0.001\end{array}$ \\
\hline Adjuvant therapy & & 0.849 & & 0.667 \\
\hline $\begin{array}{l}\text { Fibrinogen }(\mathrm{g} / \mathrm{L}) \\
\quad \leq 4.0 \text { vs }>4.0\end{array}$ & & 0.221 & & 0.333 \\
\hline $\begin{array}{l}\text { Lymphocyte }\left(10^{9} / \mathrm{L}\right) \\
\leq 1.40 \text { vs }>1.40\end{array}$ & & 0.519 & & 0.739 \\
\hline $\begin{array}{l}\text { FLR } \\
\quad \leq 3.03 * \text { vs }>3.03\end{array}$ & 1.448 (I.073-I.952) & 0.015 & $1.445(1.084-1.925)$ & 0.012 \\
\hline
\end{tabular}

Notes: *Refer to reference category. Data in bold indicate significant differences.

Abbreviation: FLR, fibrinogen-to-lymphocyte ratio.

prognosis estimation and treatment decision-making for resectable ESCC.

There are several limitations to the current study. First, as a single-center retrospective study, selection biases could not be ignored regarding data collection. Second, some confounding factors, such as accompanying infectious diseases and hematological diseases, may affect FLR level, which in turn affect the accuracy of its prognostic value. Third, the cutoff point of FLR in this study was chosen solely based on our data, and this finding needs to be validated in another patient population. Studies have reported an index that is quite similar, but included neutrophils in their index $;^{30,31}$ however, since the neutrophil count is often affected by chemotherapy, we chose to exclude neutrophils from our index to reduce confounding factors. In addition, we excluded those patients who underwent neoadjuvant therapy because it is hard to choose a suitable time-point to evaluate FLR considering the chemotherapeutic hematotoxicity. Further studies are recommended to focus on the relationship between neoadjuvant therapy and FLR level. Despite these limitations, our results provided a promising prognostic marker: FLR, which was relatively reliable, and our study had a reasonable experimental design and an appreciable sample size. Hence, we suggest that FLR could be used together with the TNM staging system as well as other plasma indexes to jointly improve the accuracy of preoperative evaluation of ESCC patients. 
Table 4 Univariate and multivariate logistic regression analyses of prognostic factors for first-year mortality

\begin{tabular}{|c|c|c|c|c|}
\hline \multirow[t]{2}{*}{ Variables } & \multicolumn{2}{|l|}{ Univariate } & \multicolumn{2}{|l|}{ Multivariate } \\
\hline & HR (95\%Cl) & $P$ & HR (95\%Cl) & $P$ \\
\hline $\begin{array}{l}\text { Gender } \\
\text { Female* vs male }\end{array}$ & $1.624(0.872-3.024)$ & 0.126 & & \\
\hline $\begin{array}{l}\text { Age } \\
\qquad \leq 60 * \text { vs }>60\end{array}$ & $1.112(0.703-1.762)$ & 0.650 & & \\
\hline $\begin{array}{l}\text { Surgical approach } \\
\text { Sweet } \\
\text { Ivor Lewis/McKeown }\end{array}$ & $\begin{array}{l}\text { I (reference) } \\
0.891 \text { (0.559-I.4I8) }\end{array}$ & 0.626 & & \\
\hline $\begin{array}{l}\text { Location } \\
\text { Upper } \\
\text { Middle } \\
\text { Lower }\end{array}$ & $\begin{array}{l}\text { I (reference) } \\
\text { I.329 (0.593-2.98I) } \\
0.942(0.4 \mid 7-2.129)\end{array}$ & $\begin{array}{l}0.358 \\
0.489 \\
0.886\end{array}$ & & \\
\hline $\begin{array}{l}\text { Tumor length } \\
\qquad \leq 4 \mathrm{~cm}^{*} \text { vs }>4 \mathrm{~cm}\end{array}$ & $2.104(1.318-3.359)$ & 0.002 & $1.772(1.082-2.903)$ & 0.023 \\
\hline $\begin{array}{l}\text { Differentiation } \\
\text { GI } \\
\text { G2 } \\
\text { G3 }\end{array}$ & $\begin{array}{l}\text { I (reference) } \\
\text { I.052 (0.572-I.935) } \\
0.823(0.4 \mid 5-1.636)\end{array}$ & $\begin{array}{l}0.671 \\
0.872 \\
0.579\end{array}$ & & \\
\hline $\begin{array}{l}\text { T category } \\
\text { T1 } \\
\text { T2 } \\
\text { T3 }\end{array}$ & $\begin{array}{l}\text { I (reference) } \\
4.460(0.987-20.152) \\
6.959(1.67 \mid-28.985)\end{array}$ & $\begin{array}{l}0.013 \\
0.052 \\
<0.001\end{array}$ & & $\begin{array}{l}0.068 \\
0.533 \\
0.062\end{array}$ \\
\hline $\begin{array}{l}\text { N category } \\
\text { N0 } \\
\text { NI } \\
\text { N2 } \\
\text { N3 }\end{array}$ & $\begin{array}{l}\text { I (reference) } \\
3.423(1.911-6.133) \\
4.012(2.075-7.755) \\
8.024(3.438-18.725)\end{array}$ & $\begin{array}{l}<0.001 \\
<0.001 \\
<0.001 \\
<0.001\end{array}$ & $\begin{array}{l}\text { I (reference) } \\
3.401 \text { (I.869-6.189) } \\
3.861 \text { (I.962-7.597) } \\
8.282(3.445-19.911)\end{array}$ & $\begin{array}{l}<0.001 \\
<0.001 \\
<0.001 \\
<0.001\end{array}$ \\
\hline $\begin{array}{l}\text { Overall morbidity } \\
\text { No* vs yes }\end{array}$ & $1.923(1.117-3.313)$ & 0.018 & $2.187(1.214-3.940)$ & 0.009 \\
\hline Adjuvant therapy & $1.799(1.107-2.922)$ & 0.018 & & 0.595 \\
\hline $\begin{array}{c}\text { Fibrinogen }(\mathrm{g} / \mathrm{L}) \\
\leq 4.0^{*} \text { vs }>4.0\end{array}$ & $2.082(1.302-3.328)$ & 0.002 & & 0.208 \\
\hline $\begin{array}{l}\text { Lymphocyte }\left(10^{9} / \mathrm{L}\right) \\
\quad \leq 1.40^{*} \text { vs }>1.40\end{array}$ & $0.530(0.315-0.890)$ & 0.016 & & 0.591 \\
\hline $\begin{array}{l}\text { FLR } \\
\qquad \leq 3.03 * \text { vs }>3.03\end{array}$ & $2.519(1.433-4.430)$ & 0.001 & $2.123(1.157-3.898)$ & 0.015 \\
\hline
\end{tabular}

Notes: *Refer to reference category. Data in bold indicate significant differences. Abbreviations: $\mathrm{Cl}$, confidence interval; FLR, fibrinogen-to-lymphocyte ratio.

In conclusion, we demonstrated that the preoperative FLR level could be used as a simple, noninvasive, inexpensive, and potentially effective indicator to evaluate the prognosis of ESCC patients following radical esophagectomy.

\section{Abbreviation list}

FLR, fibrinogen-to-lymphocyte ratio; ESCC, esophageal squamous cell carcinoma; OS, overall survival; DFS, disease-free survival; EC, esophageal cancer; PNI, prognostic nutritional index; GPS, Glasgow Prognostic Score; PLR, 
platelet-to-lymphocyte ratio; NLR, neutrophil-tolymphocyte ratio; IQR, interquartile range; $\chi^{2}$, chi-square; PDGF, platelet-derived growth factor; FGF, fibroblast growth factor; VEGF, vascular endothelial growth factor; NK cell, natural killer cell.

\section{Data availability}

The datasets used and/or analyzed during the current study are available from the corresponding author on reasonable request.

\section{Acknowledgments}

We thank the members of the Department of Thoracic Surgery at the Sun Yat-sen University Cancer Center for cooperation and assistance. The authors wish to thank Professor Rolfe for his encouragements and friendly suggestions at the beginning of this study.

This work was supported by "5010 plan" from Sun Yat-sen University (grant 2007044).

\section{Author contributions}

All authors made substantial contributions to conception and design, acquisition of data, or analysis and interpretation of data; took part in drafting the article or revising it critically for important intellectual content; gave final approval of the version to be published; and agree to be accountable for all aspects of the work.

\section{Disclosure}

The authors report no conflicts of interest in this work.

\section{References}

1. Ferlay J, Soerjomataram I, Dikshit R, et al. Cancer incidence and mortality worldwide: sources, methods and major patterns in GLOBOCAN 2012. Int $J$ Cancer. 2015;136(5):E359-E386. doi:10.1002/ijc. 29210

2. Chen W, Zheng R, Baade PD, et al. Cancer statistics in China, 2015. CA Cancer J Clin. 2016;66(2):115-132. doi:10.3322/caac.21338

3. Yang H, Liu H, Chen Y, et al. Neoadjuvant chemoradiotherapy followed by surgery versus surgery alone for locally advanced squamous cell carcinoma of the esophagus (NEOCRTEC5010): a phase III multicenter, randomized, open-label clinical trial. J Clin Oncol. 2018;36 (27):2796-2803. doi:10.1200/JCO.2018.79.1483

4. Sjoquist KM, Burmeister BH, Smithers BM, et al. Survival after neoadjuvant chemotherapy or chemoradiotherapy for resectable oesophageal carcinoma: an updated meta-analysis. The Lancet Oncology. 2011;12(7):681-692. doi:10.1016/S1470-2045(11)70142-5

5. Mantovani A, Allavena P, Sica A, Balkwill F. Cancer-related inflammation. Nature. 2008;454(7203):436-444. doi:10.1038/ nature 07205

6. Grivennikov SI, Greten FR, Karin M. Immunity, inflammation, and cancer. Cell. 2010;140(6):883-899. doi:10.1016/j.cell.2010.01.025
7. Falanga A, Schieppati F, Russo D. Cancer tissue procoagulant mechanisms and the hypercoagulable state of patients with cancer. Semin Thromb Hemost. 2015;41(7):756-764. doi:10.1055/s-0035-1564040

8. Falanga A, Marchetti M, Vignoli A. Coagulation and cancer: biological and clinical aspects. J Thromb Haemost. 2013;11(2):223-233. doi:10.1111/jth. 12075

9. Zhang H, Shang X, Ren P, et al. The predictive value of a preoperative systemic immune-inflammation index and prognostic nutritional index in patients with esophageal squamous cell carcinoma. $J$ Cell Physiol. 2019;234(2):1794-1802. doi:10.1002/jcp.27052

10. Lindenmann J, Fink-Neuboeck N, Avian A, et al. Preoperative glasgow prognostic score as additional independent prognostic parameter for patients with esophageal cancer after curative esophagectomy. Eur J Surg Oncol. 2017;43(2):445-453. doi:10.1016/j.ejso.2016.10.015

11. Yodying H, Matsuda A, Miyashita M, et al. Prognostic significance of neutrophil-to-lymphocyte ratio and platelet-to-lymphocyte ratio in oncologic outcomes of esophageal cancer: a systematic review and meta-analysis. Ann Surg Oncol. 2016;23(2):646-654. doi:10.1245/ s10434-015-4869-5

12. Mosesson MW. Fibrinogen and fibrin structure and functions. J Thromb Haemost. 2005;3(8):1894-1904. doi:10.1111/j.15387836.2005.01365.x

13. Zhang F, Wang Y, Sun P, et al. Fibrinogen promotes malignant biological tumor behavior involving epithelial-mesenchymal transition via the $\mathrm{p}-\mathrm{AKT} / \mathrm{p}-\mathrm{mTOR}$ pathway in esophageal squamous cell carcinoma. J Cancer Res Clin Oncol. 2017;143(12):2413-2424. doi:10.1007/s00432-017-2493-4

14. Perisanidis C, Psyrri A, Cohen EE, et al. Prognostic role of pretreatment plasma fibrinogen in patients with solid tumors: A systematic review and meta-analysis. Cancer Treat Rev. 2015;41(10):960-970. doi:10.1016/j.ctrv.2015.10.002

15. Kou F, Lu Z, Li J, et al. Pretreatment lymphopenia is an easily detectable predictive and prognostic marker in patients with metastatic esophagus squamous cell carcinoma receiving first-line chemotherapy. Cancer Med. 2016;5(5):778-786. doi:10.1002/cam4.638

16. Ray-Coquard I, Cropet C, Van Glabbeke M, et al. Lymphopenia as a prognostic factor for overall survival in advanced carcinomas, sarcomas, and lymphomas. Cancer Res. 2009;69(13):5383-5391. doi:10.1158/0008-5472.CAN-08-3845

17. Rice TW, Ishwaran H, Hofstetter WL, Kelsen DP, Apperson-Hansen C, Blackstone EH. Recommendations for pathologic staging (pTNM) of cancer of the esophagus and esophagogastric junction for the 8th edition AJCC/UICC staging manuals. Dis Esophagus. 2016;29 (8):897-905. doi:10.1111/dote.12533

18. Camp RL, Dolled-Filhart M, Rimm DL. X-tile: a new bio-informatics tool for biomarker assessment and outcome-based cut-point optimization. Clin Cancer Res. 2004;10(21):7252-7259. doi:10.1158/1078-0432.CCR-04-0713

19. Martino MM, Briquez PS, Ranga A, Lutolf MP, Hubbell JA. Heparin-binding domain of fibrin(ogen) binds growth factors and promotes tissue repair when incorporated within a synthetic matrix. Proc Natl Acad Sci U S A. 2013;110(12):4563-4568. doi:10.1073/ pnas. 1221602110

20. Witsch E, Sela M, Yarden Y. Roles for growth factors in cancer progression. Physiology (Bethesda). 2010;25(2):85-101. doi:10.1152/ physiol.00045.2009

21. Staton CA, Brown NJ, Lewis CE. The role of fibrinogen and related fragments in tumour angiogenesis and metastasis. Expert Opin Biol Ther. 2003;3(7):1105-1120. doi:10.1517/14712598.3.7.1105

22. Davalos D, Akassoglou K. Fibrinogen as a key regulator of inflammation in disease. Semin Immunopathol. 2012;34(1):43-62. doi:10.1007/s00281-011-0290-8

23. Jennewein C, Tran N, Paulus P, Ellinghaus P, Eble JA, Zacharowski K. Novel aspects of fibrin(ogen) fragments during inflammation. Mol Med. 2011;17(5-6):568-573. doi:10.2119/molmed.2010.00146 
24. Steinbrecher KA, Horowitz NA, Blevins EA, et al. Colitis-associated cancer is dependent on the interplay between the hemostatic and inflammatory systems and supported by integrin alpha(M)beta(2) engagement of fibrinogen. Cancer Res. 2010;70(7):2634-2643. doi:10.1158/0008-5472.CAN-09-3465

25. Palumbo JS, Talmage KE, Massari JV, et al. Tumor cell-associated tissue factor and circulating hemostatic factors cooperate to increase metastatic potential through natural killer cell-dependent and-independent mechanisms. Blood. 2007;110(1):133-141. doi:10.1182/blood-2007-01065995

26. Palumbo JS. Mechanisms linking tumor cell-associated procoagulant function to tumor dissemination. Semin Thromb Hemost. 2008;34 (2):154-160. doi:10.1055/s-2008-1079255

27. Dougan M, Dranoff G. Immune therapy for cancer. Annu Rev Immunol. 2009;27:83-117. doi:10.1146/annurev.immunol.021908.132544
28. Pines G, Klein Y, Buyeviz V, Idelevich E, Kashtan H. Disease-related mortality within the first year after subtotal esophagectomy for cancer. Ann Surg Oncol. 2011;18(4):1139-1144. doi:10.1245/s10434-010-1386-4

29. Nassri A, Zhu H, Wang DH, Ramzan Z. Serum albumin at diagnosis is an independent predictor of early mortality in veteran patients with esophageal cancer. Nutr Cancer. 2018;70(8):1246-1253.

30. Arigami T, Okumura H, Matsumoto M, et al. Analysis of the fibrinogen and neutrophil-lymphocyte ratio in esophageal squamous cell carcinoma: a promising blood marker of tumor progression and prognosis. Medicine (Baltimore). 2015;94(42):e1702. doi:10.1097/ MD.0000000000000874

31. Kijima T, Arigami T, Uchikado Y, et al. Combined fibrinogen and neutrophil-lymphocyte ratio as a prognostic marker of advanced esophageal squamous cell carcinoma. Cancer Sci. 2017;108 (2):193-199. doi:10.1111/cas.13127

\section{Publish your work in this journal}

Cancer Management and Research is an international, peer-reviewed open access journal focusing on cancer research and the optimal use of preventative and integrated treatment interventions to achieve improved outcomes, enhanced survival and quality of life for the cancer patient.
The manuscript management system is completely online and includes a very quick and fair peer-review system, which is all easy to use. Visit http://www.dovepress.com/testimonials.php to read real quotes from published authors. 